\title{
Algunas calas en el uso de los nombres de color en El Quijote
}

\author{
Gerardo FERnÁndez SAN EMETERIO*
}

\section{Antecedentes EN El USO DE LOS NOMBRES DE COLOR, DE Alfonso X al Romancero Nuevo (ESTADO DE LA CUESTIÓN)}

Entre los siglos XV y XVII, se produce en la literatura castellana un uso claramente diferenciado de los nombres de color. Durante la Edad Media, el uso de dichos nombres había sido escaso; como señala R. M. Duncan, autor de varios trabajos dedicados a los adjetivos de color en el Medievo castellano, "los escritores del Medievo español no tenían los ojos abiertos al color del mundo de la naturaleza que les rodeaba". ${ }^{1}$ Abundando en ello años después, señalaba también como "if we omit references to blanco and negro (which are abundant in most medieval Spanish text) we note very few instances of adjectives of color" 2 . Tanto es así que, siempre según el citado investigador, "el autor del Libro de Alexandre esquiva la oportunidad de mencionar colores especiales"3, y ello a pesar de que, siempre según Duncan, se trata de "the 'literary' work of the thirteenth century which makes the greatest use of adjectives of color" 4 .

El hecho es que dicha escasez en el uso no se debía, de nuevo siguiendo a Duncan, a falta de términos para expresar el color, ${ }^{5}$ sino probablemente a que no consideraban preciso el detalle en este punto. Ello parece concluirse del

\footnotetext{
* Escuela Municipal de Música "Federico Chueca" de Madrid.

1. R. M. Duncan, "Adjetivos de color", p. 463.

2. R. M. DunCan, "Color Words", p. 54.

3. R. M. DunCan, "Adjetivos de color", p. 463.

4. R. M. DunCan, "Color Words", p. 54.

5. R. M. DunCan, "Color Words", p. 55.
} 
hecho de que los primeros testimonios conservados de un uso detallado de los nombres de color se encuentren en la prosa científica alfonsí. De nuevo en palabras de Duncan, su "desarrollo es una necesidad impuesta por el creciente interés por la ciencia"6 y se plasmó de forma especial en la redacción del $L a$ pidario, en el que era preciso describir gran cantidad de matices de colores en las piedras.

Más adelante, la prosa de la ficción sentimental muestra un uso frecuente, pero distinto, de los nombres de color que ha sido estudiado por Harriet Goldberg. Dicha autora se centra en este tipo de literatura porque en ella "architectural marvels, banners, shields, gowns, tunies and hose are colorful embellishments" y "because its authors use colour adjectives in a context somewhat oriented to reality, and frequently add on explanation of what they mean"8.

Posteriormente, este código de colores parece haberse refugiado en el Romancero Nuevo y en la literatura de carácter popular, frente a la escasez en la poesía "outside the ballads and pastoral references" bias señalaba en el Tesoro (1611) que "tienen las colores, en el vulgo, sus significaciones particulares, que todos las saben" 10 .

De este modo, y como señala H. A. Kenyon, el significado de este colorido con frecuencia es compartido por autor y lectores, por lo que sólo a veces siente aquél la necesidad de explicarlo ${ }^{11}$. En este punto, destaca el mismo unos versos en los que se evita nombrar el color de la vestimenta de un caballero porque "son las colores que viste / conforme al mal que pasa"12.

En cuanto a la vigencia de este código de colores, Kenyon propone como terminus ante quem la Cárcel de amor de San Pedro y como terminus a quo el año de 1650, puntualizando que "it was [...] in the latter part of the sixteenth century that this symbolism had its greatest development and evident popularity"13. Probablemente el desarrollo de la poesía gongorina, cuyo gusto por lo sensual empleaba el colorido de muy diferente manera, tuvo su importancia en el declive de este código de colores.

Por su parte, Ian Macpherson, al editar el cancionero de Timoneda titulado Dechado de colores, ha señalado escasa consistencia de este uso simbólico, toda vez que a pesar de estar "based firmly upon the heraldic tinctures of blazonry which provided the earliest basis for the system" 14 , cambiaba en los

6. R. M. DunCAN, “Adjetivos de color”, p. 463.

7. H. GoldBerG, "A Reappraisal of Color Symbolism”, p. 221.

8. H. GoldBerG, "A Reappraisal of Color Symbolism”, nota 1.

9. H. KenYon, "Color Symbolism", p. 337.

10. Covarrubias, S. DE, Tesoro, $s$ v "color".

11. Véase también H. GoldBerg, "A Reappraisal of Color Symbolism”, nota 221.

12. H. Kenyon, "Color Symbolism”, p. 328. Los versos remiten al número 145 del Romancero de Durán. Desgraciadamente, no da Kenyon el primer verso de ninguno de los romances que cita, limitándose a dar su número dentro de la obra citada.

13. H. KenYon, "Color Symbolism”, p. 339.

14. I. MacPherson, "Juan Timoneda's Dechado de colores", p. 51. Asimismo, H. GoldBerG, “A Reappraisal of Color Symbolism”, p. 222. 
diferentes países ${ }^{15}$. Sin embargo, aunque los matices puedan ser, y de hecho son, introducidos por cada autor, el significado general de la gama de colores debía de ser, al menos en España, lo suficientemente común como para que Juan de Segura, en el Proceso de cartas de amores, "uses the custom of revealing one's feeling chromatically to portray the lovers' tentative steps toward intimacy"16 y, más adelante, realizara Covarrubias la afirmación a la que he hecho referencia líneas atrás.

Advierte también Macpherson de la posibilidad de que un uso concreto pueda desarrollarse de forma especial en un autor determinado. Su comparación del Dechado de colores con el soneto "Es lo blanco castísima pureza" de Gutierre de Cetina muestra la coincidencia en los significados básicos de los colores, pero alerta también sobre lo que él llama "individual colors"17. En este sentido, señala del Dechado que el código presente en él "come together as a coherent system, but it is a system characteristic of an individual author and time" 18 . Creo, no obstante, que las diferencias individuales se producen dentro de un código compartido sin cuya existencia Timoneda no se hubiera molestado en sacar a la luz un cancionerillo como el Dechado de colores que edita Macpherson.

Sí es cierto, en cambio, que, como señala Harriet Goldberg respecto de la ficción sentimental, hay usos del color "realistic and not symbolic", por lo que no conviene agotar cada caso ${ }^{19}$. Si ello es así en los autores de la ficción sentimental o de los libros de caballerías, cuánto más lo será en el caso de Cervantes, que está quebrantando los límites de estos géneros.

Por otra parte, creo que nos hallamos ante un uso no sólo simbólico, sino también subjetivo de determinados nombres de color. En el caso de gamas como la del rojo, el empleo de un nombre u otro puede no indicar tanto diferentes colores como diferentes puntos de vista del narrador o elementos que dicho narrador quiere destacar para caracterizar al personaje que presenta. $\mathrm{Me}$ lleva a pensar esto la conclusión de H. Goldberg:

In some instances [entre las que incluye los colores leonado, pardo y cárdeno] it has not been possible to assign an objective chromatic value to some colour adjectives because of the difficulties inherent to colour perception and naming ${ }^{20}$.

Este uso simbólico y subjetivo se mantiene en la obra de Cervantes, bien que no sea exclusivo. Es evidente el tiempo que ha pasado desde la ficción sentimental y que los narradores cuentan con otros medios para retratar el carácter del personaje, pero ello no supone que el código se abandone de forma repentina.

15. I. MACPHERSON, "Juan Timoneda's Dechado de colores", p. 50.

16. H. Goldberg, "A Reappraisal of Color Symbolism”, nota 223.

17. I. MACPHERSON, "Juan Timoneda's Dechado de colores", p. 53.

18. I. MACPHERSON, "Juan Timoneda's Dechado de colores", p. 59.

19. H. GoldBerG, "A Reappraisal of Color Symbolism", p. 224.

20. H. GoldBerG, "A Reappraisal of Color Symbolism”, p. 232. 


\section{Cervantes y el uso Puntual Del Código DE LOS COLORES}

Cervantes escribe, por lo tanto, en un tiempo en que el uso del código de nombres de color está superado, pero todavía lo usa de forma puntual. Junto con ello, probablemente relacionado con ello, tenemos un uso destacado, aunque no simbólico, de algunos colores en determinados contextos.

Hay que tener en cuenta en primer lugar que el empleo de los nombres de color se realiza, como era habitual en la época, con una gran economía, como evitando un uso no ya excesivo, sino general, de dichos nombres. Ejemplo claro me parece que en la aventura con el cuerpo muerto (Capítulo XIX de la primera parte de Don Quijote), que sucede de noche, no se mencione ni una sola vez el término negro, probablemente sentido como redundante. Sin embargo, a continuación, en el pasaje previo a la aventura de los batanes, cuando Don Quijote y Sancho se sientan a cenar en un prado, nos encontramos con lo siguiente:

$\mathrm{Y}$ a poco trecho que caminaban entre dos montañuelas se hallaron en un espacioso y escondido valle, donde se apearon y Sancho alivió el jumento; y tendidos sobre la verde yerba, con la salsa de su hambre, almorzaron, comieron, merendaron y cenaron a un mismo punto ${ }^{21}$.

El color verde, que no podían percibir los ojos de los personajes, recordemos que es noche oscura, aparece para que el lector comience a ser consciente, antes incluso que ellos, de la frescura y humedad del prado, de modo que, cuando Sancho sienta sed y caiga en la cuenta de que no tienen agua, la humedad del prado ("colmado de verde y menuda yerba")22 le lleve a pensar que debe de haber agua cerca y ello sirva de hilo hacia la aventura de los batanes que se va a narrar en el Capítulo XX:

No es posible, señor mío, sino que estas yerbas dan testimonio de que por aquí cerca debe de estar alguna fuente o arroyo que estas yerbas humedece, y, así, será bien que vamos un poco más adelante, que ya toparemos donde podamos mitigar esta terrible sed que nos fatiga, que sin duda causa mayor pena que la hambre ${ }^{23}$.

Y toda esta insistencia en el color verde dentro de un ambiente de noche oscura está conectado con la descripción que del lugar en que se encuentran los personajes hace Cervantes: un locus amoenus vuelto del revés en el que, de nuevo, no se hace mención directa de color alguno:

Era la noche, como se ha dicho, escura, y ellos acertaron a entrar entre unos árboles altos, cuyas hojas, movidas del blando viento, hacían un te-

21. Don Quijote, I, XIX, ed. cit., p. 173.

22. Don Quijote, I, XIX, ed. cit., p. 174.

23. Don Quijote, I, XX, ed. cit., p. 174. 
meroso y manso ruido, de manera que la soledad, el sitio, la escuridad, el ruido del agua con el susurro de las hojas, todo causaba horror y espanto $^{24}$.

Poco después, Sancho va a insistir en el color verde de la hierba cuando propone a su amo que se apee de Rocinante y se eche "a dormir un poco sobre la verde yerba, a uso de caballeros andantes" 25 . Con ello, aunque se trate de un epíteto gastado y tengamos la impresión de que el escudero está imitando el habla de su amo, se insiste en el color para que no olvidemos la frescura del paraje de modo que la transición a la aventura de los batanes sea lo más fluida posible; nunca mejor, tratándose de agua.

De este modo, Cervantes selecciona un color e insiste en él con una finalidad narrativa, pero sin incluir simbología alguna. Creo que este recurso no hubiera sido posible si no se hubiera tenido una atención especial al uso de los nombres de color mediante el código al que me vengo refiriendo.

Por otra parte, como muestra de que es un código en descomposición, Cervantes lo utiliza de forma satírica. Ya, Kenyon, al estudiar el sentido simbólico del color en el Romancero Nuevo se da cuenta de que

In the latter part of the sixteenth or in the early seventeenth century this symbolism came into such common use that the kaleidoscopic costume of the amorous young men became rather a laughing-stock and offered a fit for the attacks of the satyrists ${ }^{26}$.

Cervantes no es ajeno a este tipo de sátiras en la vestimenta cortesana; tal parece la descripción del traje de la novia en El casamiento engañoso:

Y, aunque quisiera replicarle a esto, no me dio lugar la señora doña Clementa Bueso, que se entró en la sala, vestida de raso verde prensado, con muchos pasamanos de oro, capotillo de lo mismo y con la misma guarnición, sombrero con plumas verdes, blancas y encarnadas, y con rico cintillo de oro, y con un delgado velo cubierta la mitad del rostro ${ }^{27}$.

La mezcla absurda de verde, blanco y encarnado (esperanza, castidad y crueldad) no parece casual, sino encaminada a hacer mayor la burla del que está siendo engañado, al tomar al lector, mediante la presencia de estos colores en la descripción de la salida de la novia, como cómplice en el engaño. Otro uso satírico es el del código heráldico de los colores al hacer parodia del mundo caballeresco en el episodio del combate de los dos ejércitos, en realidad rebaños, en el capítulo XVIII de la primera parte de Don Quijote:

24. Don Quijote, I, XX, ed. cit., p. 174.

25. Don Quijote, I, XX, ed. cit., p. 177.

26. H. KenYon, "Color Symbolism”, p. 253.

27. El casamiento engañoso, edición de Florencio Sevilla Arroyo y Antonio Rey Hazas, Alcalá de Henares, Centro de Estudios Cervantinos, 1994, p. 200. 
Aquel caballero que allí ves de las armas jaldes, que trae en el escudo un león coronado, rendido a los pies de una doncella, es el valeroso Laurcalco, señor de la Puente de Plata; el otro de las armas de las flores de oro, que trae en el escudo tres coronas de plata en campo azul, es el temido Micocolembo, gran duque de Quirocia; [...]. Pero vuelve los ojos a estotra parte y verás delante y en la frente de estotro ejército al siempre vencedor y jamás vencido Timonel de Carcajona, príncipe de la Nueva Vizcaya, que viene armado con las armas partidas a cuarteles, azules, verdes, blancas y amarillas, y trae en el escudo un gato de oro en campo leonado, [...]; el otro que carga y oprime los lomos de aquella poderosa alfana, que trae las armas como nieve blancas y el escudo blanco y sin empresa alguna, es un caballero novel, de nación francés, llamado Pierres Papín, [...]; el otro que bate las ijadas con los herrados carcaños a aquella pintada y ligera cebra y trae las armas de los veros azules, es el poderoso duque de $\mathrm{Nerbia}^{28}$.

Sin embargo, el color es aquí un elemento más, por un uso absurdo en el que predomina el azul, de la chacota a la que se somete la fantástica descripción de armas y escudos habitual en los libros de caballerías, y que incluye empresas tan inverosímiles como "tres coronas de plata" o, sobre todo, "un gato de oro en campo leonado", donde se subvierte el sentido del propio escudo del caballero que, si incluía animales, debía, según Diego de Valera, pintarlos "segunt naturalmente más vigor han o más fermosos se pueden mostrar" 29 y donde el leonado no tiene tanto valor cromático o simbólico cuanto de chiste que da como resultado la pintura de un gato que aspira a león.

Una nueva referencia burlesca al código caballeresco de los colores aparece en la conversación de Don Quijote y Sancho con el fantástico primo del licenciado que lo acompaña a la Cueva de Montesinos. Éste, autor de libros absurdos, tiene en proyecto.

Uno que se intitulaba el de las libreas, donde pinta setecientas y tres libreas, con sus colores, motes y cifras, de donde podían sacar y tomar las que quisiesen en tiempo de fiestas y regocijos los caballeros cortesanos, sin andarlas mendigando a nadie, ni lambicando, como dicen, el cerbelo por sacarlas conformes a sus deseos e intenciones ${ }^{30}$.

Con todo, pervive en Cervantes el uso del código de colores. Mis calas en textos cervantinos, en especial del Quijote, me llevan a deducir que lo usa en el caso de personajes secundarios a los que no tiene mucho tiempo para caracterizar, pero cuyo carácter y destino necesita dejar claro en un golpe de vista. Vamos a detenernos en algunos casos. 


\section{II.1. El episodio de Sierra Morena y los sucesos de la venta}

En la Primera Parte, estos episodios, con su acumulación de personajes, dan lugar a un uso frecuente del código de los colores, tanto en la vestimenta de cada uno, como en los disfraces que a veces utilizan para aludir simbólicamente a su condición, a su carácter o a su destino.

El primer caso es el de Cardenio. El personaje se presenta por primera vez como una exhalación a los ojos de Don Quijote y Sancho:

Yendo, pues, con este pensamiento, vio que por cima de una montañuela que delante de los ojos se le ofrecía iba saltando un hombre de risco en risco y de mata en mata con extraña ligereza. Figurósele que iba desnudo, la barba negra y espesa, los cabellos muchos y rabultados, los pies descalzos y las piernas sin cosa alguna; los muslos cubrían unos calzones, al parecer de terciopelo leonado, mas tan hechos pedazos, que por muchas partes se le descubrían las carnes ${ }^{31}$.

El color leonado "denota gravedad y firmeza" 32 según Timoneda y ambas son características que cuadran a Cardenio, tal vez demasiado grave y demasiado firme, que queda, así, caracterizado de inmediato con el color de sus calzones. Por su parte, Kenyon lo da como "another variant of the idea expressed by yellow" 33 y propone como significado "sorrow or trouble in some guise" 34 . Finalmente, recordemos que el leonado es uno de los colores para los que Goldberg no encontraba "an objective chromatic value" 35 , por lo que su presencia en la descripción parece aún más motivada por el carácter del personaje que por dar una nota anecdótica de color.

Sin embargo, más allá del color de los calzones, el propio nombre del personaje podría estar dando pistas sobre su carácter desde antes de que empiece a narrarnos su historia. El nombre de Cardenio pudiera proceder del adjetivo "cardeno", con acentuación llana, que según Duncan "es el adjetivo que sirve más para indicar el color azul en la obra alfonsí, que es donde abunda más" 36 . Sin embargo, la mayor parte de los testimonios, incluida la entrada en el Diccionario de Autoridades, se refieren a él como "el color morado, como el del lirio". Por su parte, Martín Alonso lo hace proceder del latín vulgar cardinus, derivado de cardus, "cardo" e insiste en que, más que de un azul, se

31. Don Quijote, I, XXIII, ed. cit., p. 216. No pasó por alto a Cervantes que lo minucioso de la descripción resultaba excesivo para alguien a quien se ve de lejos y deprisa, por lo que añadió a renglón seguido: "aunque pasó con la ligereza que se ha dicho, todas estas menudencias miró y notó el Caballero de la Triste Figura".

32. Dechado, villancico 3, ed. Macpherson, p. 39.

33. H. KenYON, “Color Symbolism”, p. 332.

34. H. KenYon, "Color Symbolism", p. 333. A todo ello añade Kenyon el sentido de "a sort of 'let-me-alone' symbol”. El amarillo significa para Timoneda "desesperación” (Dechado, villancico 3, ed. Macpherson, p. 39).

35. H. Goldberg, “A Reappraisal of Color Symbolism”, p. 232. Vid. La cita en extenso supra, p. 3.

36. R. M. Duncan, “Adjetivos de color”, p. 467. 
trata de un "color amoratado". Corominas y Pascual, por su parte, matizan que el color cárdeno procede de cardo por el color morado de las flores de dicha planta y puntualizan que aunque "significó primero 'azul' o 'azulado",, para Nebrija "era ya luridus = 'lívido"”, en su sentido etimológico de "amoratado".

Por su parte, Harriet Goldberg considera que "cárdeno (identified by Matulka as purple) appears sometimes in contexts where it might mean blue and sometimes blue-violet)" 37 .

En nota incluida en la reciente edición del Quijote publicada bajo los auspicios del Instituto Cervantes, señala Alberto Sánchez que

el nombre de Cardenio, totalmente literario y posiblemente derivado del cardo silvestre (dado el carácter híspido y arisco en que se nos muestra), no de ningún personaje histórico de su tiempo ${ }^{38}$.

Reyre, en su diccionario, lo supone un "nom à valeur toponymique (endroit couvert de cardons), anthroponimique (caractéristique d'un fief ou d'un lieu d'origine)"39. La segunda hipótesis, defendida por Rodríguez Marín, ya fue desmontada por Dámaso Alonso en el artículo que dedicó al nombre. Se suponía que el personaje cervantino era trasunto del poeta cordobés don Pedro de Cárdenas, pero, señala Alonso, "Cardenio, como nombre poético, no es del todo infrecuente" 40 . Sin ir más lejos, el propio Cervantes lo usó para el protagonista de La entretenida, y Lope lo usó como uno de sus alter ego en La escolástica celosa o La fábula de Perseo, llegando, incluso, a darle un carácter jovial a personajes de este nombre en La Arcadia y El marqués de Mantua $^{41}$.

En cuanto a la hipótesis que hace proceder el nombre de la planta del cardo, creo que Cardenio es bastante más que lo que coloquialmente llamamos "un cardo" y bajo su aspereza (por otra parte episódica) esconde un personaje apasionado que, como señala H. Satake, "vive obsesionado por lo aparente" 42 . El hecho de que el color cárdeno sea el color de la enfermedad y uno de los colores relacionados con la melancolía me lleva a pensar en ello. Con este valor encontramos el uso de cardeno, en textos como la traducción de Fray Vicente de Burgos del El Libro de Propietatibus Rerum de Bartolomé Anglicus, donde leemos:

37. H. Goldberg, “A Reappraisal of Color Symbolism”, p. 230. La autora hace eferencia al estudio ya clásico de Barbara Matulka The novels of Juan de Flores and their european diffusion, Nueva York, Institut of French Studies, 1931.

38. Don Quijote, edición del Instituto Cervantes, II, p. 66.

39. D. ReYRe, Dictionnarie, p. 58.

40. D. Alonso, "Lope, Don Pedro de Cárdenas y los Cardenios", p. 71.

41. D. Alonso, "Lope, Don Pedro de Cárdenas y los Cardenios", pps. 79-85. Queda por averiguar hasta qué punto comparten estos Cardenios el carácter melancólico y furioso del cervantino y hasta qué punto se apropió Lope del nombre para dotarlo, como hacía siempre el Fénix, de contenido propio.

42. K. Satake, "En torno a Cardenio en el Quijote", p. 94. 
ca, segund dize Tholomeo en el libro de los Juizios de las Estrellas, Saturno haze el ombre feo, amarillo o cardeno \& de malvadas obras, pereçoso \& pesan, triste $\&$ podrido $\&$ tarde alegre o reyente ${ }^{43}$.

Juan Fernández de Heredia aconseja en El Secreto secretorum: "Asi, tu fuye de todo honbre que sera de color cardeno et amariello, porque aquesti tal muyto es enclinado a luxuria et a pecados"44. Más aún, el mismo texto que traducía Fray Vicente de Burgos dedica su capítulo XXI a "la malicia deste color" y destaca de él lo siguiente:

Este color es malo en los cuerpos animados ca el muestra la superabundançia de frialdad que mata el calor natural \& la mortificaçion que comiença del animal o muestra grand superfluidad de la sangre malenconica que corrompe o gasta la superfiçie de la peleja o muestra congoxa de coraçon que revoca assi su sangre como pareçe en los llagados \& asotados o es señal este color de falta despiritos \& de calor natural como pareçe en los idropicos \& en los eticos, como dize Egidio $^{45}$.

El propio Reyre recuerda que el nombre "évoque les coups (cardenio, cardenales)" 46 y que "cardeno" sea el nombre con el que se refieren numerosos textos al golpe que hoy conocemos como cardenal $^{47}$, y pertenezca a la misma gama que el morado (el color del amor por excelencia $)^{48}$, me llevan a pensar en la posibilidad de que el nombre proceda más del color cárdeno que de la planta de la que originariamente toma su nombre.

Lo mismo sucede en textos más cercanos a Cervantes: el colombiano Pedro de Solís y Valenzuela, en El desierto prodigioso y prodigio del desierto describe el cuerpo de Cristo crucificado como "Cuerpo lastimado y cárdeno, a compassión movía"49. Y Duque de Estrada describe un combate de púgiles incluyendo el cárdeno entre los colores de las heridas:

aferrándose con tal furia y apretándose con tal fuerza que las costillas se rompieron con los nudos de los dedos, el pecho con las barbas, las caras con las cabezas, pues donde ponían alguno de estos miembros lo dejaban lívido, cárdeno, amarillo y negro, cuanto las mismas colores lo son ${ }^{50}$.

43. Fray Vicente de Burgos, Traducción de El Libro de Propietatibus Rerum de Bartolomé Anglicus, fol. $124 \mathrm{v}$.

44. J. FERNÁNDEZ de HeREDIA, El Secreto secretorum, fol. 317r.

45. Fray Vicente de Burgos, Traducción de El Libro de Propietatibus Rerum de Bartolomé Anglicus, fol. 301v.

46. D. ReYre, Dictionnarie, p. 58.

47. CoRDE recoge testimonios en los fueros de Burgos, Medinaceli, Usagre, Zorita de los Canes o Cáceres.

48. Dechado, villancico 1, ed. Macpherson, p. 38.

49. El desierto prodigioso y prodigio del desierto, edición de Rubén Páez Patiño, Bogotá, Instituto Caro y Cuervo, 1977 - 1985, vol. III, p. 10.

50. Diego DuQue de Estrada, Comentarios del desengañado de sí mismo. Vida del mismo autor, edición de Henry Ettinghausen, Madrid, Castalia, 1982, p. 395. 
También Jerónimo de Huerta, en su traducción de Plinio, dice del herido por el basilisco: "Aecio afirma que el que a sido herido d'él siente luego un ardor que se abrasa, pónese su cuerpo cárdeno, cáesele el cabello y pierde en un momento la vida" ${ }^{\prime \prime}$.

Más allá del apoyo textual, me lleva a pensarlo también el carácter apasionado del personaje, capaz de conducirlo a episodios de locura furiosa que recuerdan (probablemente en parte ridiculizan) al Orlando furioso de Ariosto. Como recuerda K. Satake, su amor

No es el amor puro ni el amor cortés de tipo quijotesco. Es el amor que en cualquier impulso se convierte en pasión, celos, odio y locura ${ }^{52}$.

Otro caso de uso simbólico del color es la vestimenta con la que se presenta Dorotea a lo largo de su historia. Cuando aparece por primera vez a los ojos de Cardenio, el cura y el barbero,

traía puesto un capotillo pardo de dos haldas, muy ceñido al cuerpo con una toalla blanca. Traía asimismo unos calzones y polainas de paño pardo, y en la cabeza una montera parda ${ }^{53}$.

El pardo significa "trabajo", en el sentido de "preocupación" o "problema", y verdaderamente que no son pocos los que la pobre Dorotea lleva ${ }^{54}$. Su presentación vestida de pardo (con mención explícita y tres veces reiterada del color) y ceñida de blanco (la inocencia y la pureza) se completa con el momento en que, siempre para asombro de los ocultos espectadores, sus cabellos dorados la cubren de modo que "sin no eran los pies, ninguna cosa de su cuerpo se parecía" 55 . El pardo desaparece bajo el brillo del oro que la cubre; apenas necesitamos recordar el sentido de "majestad" que acompaña al oro ${ }^{56}$. La continuación con el vestido de Micomicona, del que sólo se destaca el color de "una mantellina de otra vistosa tela verde" 57 , color que hasta la actualidad mantiene sus significado de esperanza ${ }^{58}$, avanza en cierta medida que Dorotea va a lograr sus fines.

51. Cayo Plinio Segundo; Historia natural, trad. de Jerónimo de Huerta, libro VIII, cap. XXI, p. 393a.

52. K. SATAKE, "En torno a Cardenio en el Quijote", p. 100.

53. Don Quijote, I, XXVIII, ed. cit., p. 275.

54. Goldberg señala ejemplos en la Sepultura de Guevara, la Cárcel de amor, la Questión de amor y el soneto de Cetina ya citado ("es lo pardo trabajo"), "A Reappraisal of Color Symbolism", p. 231. A ellos podemos añadir el del noveno villancico del Dechado de colores, donde "si sale la dama de pardo escuro, denota trabajo" (ed. Macpherson, p. 43), bien que en este texto sea trabajo que la dama impone al caballero. Es preciso añadir que el Dechado no incluye símbolo alguno para el pardo claro.

55. Don Quijote, I, XXVIII, ed. cit., p. 276.

56. Dechado, villancico 14, ed. Macpherson, p. 46.

57. Don Quijote, I, XXIX, ed. cit., p. 291. Creo necesario apuntar que el "otra" indica que la tela, y por lo tanto el color de la mantellina, es diferente del de vestido de "cierta telilla rica".

58. H. KenYon, "Color Symbolism”, p. 340. 
Dentro de los mismos episodios, e inserto en la narración de Cardenio, tenemos un detalle que considero de gran interés en la descripción del traje de novia de Luscinda:

No me dio lugar mi suspensión y arrobamiento para que mirase y notase en particular lo que traía vestido: solo pude advertir a las colores, que eran encarnado y blanco, y en las vislumbres que las piedras y joyas del tocado y de todo el vestido hacían, a todo lo cual se aventajaba la belleza singular de sus hermosos y rubios cabellos, tales, que, en competencia de las preciosas piedras y de las luces de cuatro hachas que en la sala estaban, la suya con más resplandor a los ojos ofrecían ${ }^{59}$.

Puede llamar la atención la presencia del encarnado, color que simboliza la crueldad ${ }^{60}$, en el traje de la novia, más aún si lo contrastamos con el blanco que lo acompaña, pero si pensamos que es Cardenio quien narra el suceso, un personaje apasionado, con fuerte tendencia a fiarse de las apariencias y a tomar las cosas "por donde queman" (y todo ello en el momento más duro de toda su narración) tal vez la cosa no sea tan extraña. Creo que podemos pensar que, de habérsenos dado la descripción desde el punto de vista de Don Fernando, el color se hubiera denominado "burel", "carmesî" o "colorado", símbolos de la lealtad y la alegría. Es el caso también de la túnica que viste Basilio cuando irrumpe en las bodas de Camacho y Quiteria en la segunda parte:

A cuyas voces y palabras todos volvieron la cabeza, y vieron que las daba un hombre vestido, al parecer, de un sayo negro jironado de carmesí a llamas. Venía coronado, como se vio luego, con una corona de funesto ciprés; en las manos traía un bastón grande ${ }^{61}$.

La superposición del carmesí y el negro muestra también de entrada la confianza en sí mismo de Basilio, rasgo suyo que se confirmará cuando lo veamos actuar.

\section{II.2. Uso simbólico en vestimentas y episodios de la Segunda Parte}

El primer caso del que me voy a ocupar es el de don Diego de Miranda, llamado por Don Quijote “el Caballero del Verde Gabán”, personaje controvertido dentro de los del Quijote. Su carácter y la causa de su aparición en la novela han sido discutidos por la crítica, dado que su presencia no hace progre-

59. Don Quijote, I, XVII, ed. cit., p. 269. p. 44.

60. Dechado, villancico 11, "Si sale la dama de encarnado, denota crueldad" ed. Macpherson,

61. Don Quijote, II, XXI, ed. cit., p. 708. 
sar la historia, ni la locura del caballero, sino que sirve simplemente de remanso reflexivo. Marcel Bataillon equiparó la aparición de don Diego en la segunda parte con la del canónigo en la primera:

¿Cuáles son los personajes que intervienen en la historia de Don Quijote y Sancho sin plantear aventura ni conflicto, dando ocasión a episodios en que la expresión de las ideas sustituye a la acción? Esto se da señaladamente en dos casos: el del canónigo en la Primera Parte, el del Caballero del Verde Gabán en la Segunda. A esta consideración se debe probablemente la sospecha bastante difundida de que ambos entran en la novela para expresar ideas simpáticas a Cervantes ${ }^{62}$.

Bataillon aboga, verosímilmente, porque el "ideal moral y religioso"63 de Cervantes sea un prototipo de "una vida sencilla, holgada, piadosa y benefactora, sin sombra de farisaísmo, [...] rigurosamente conforme al ideal erasmiano" ${ }^{4}$, un "ideal de piedad laica"65.

A ojos actuales, la atildada y multicolor vestimenta del caballero puede resultar inadecuada. Desde luego, llama la atención tanto por su colorido como por el detalle con que el narrador se recrea en ello. En un artículo dedicado a este personaje, Alberto Sánchez declaraba:

No estamos muy de acuerdo con que el vestido y adornos verdes sean los adecuados a la edad y el estado del caballero [...]. El color verde más bien era de jóvenes o de justadores en fiestas cortesanas ${ }^{66}$.

Sin embargo, como apunta Luis Andrés Murillo en nota a su edición del Quijote, "verde era color usual para trajes de viaje"67. A pesar de ello, no creo, como con cierta inocencia hace el propio Murillo, que esta vestimenta recalque "el aire festivo y primaveral de esta serie de aventuras"68. Muy al contrario, creo que con este vestido pretende el autor dar una etopeya del personaje, etopeya en la que de nuevo se emplea el código de los colores, probablemente como forma de destacarlo de inmediato y de centrar la atención sobre él. Don Diego aparece

... vestido un gabán de paño fino verde, jironado de terciopelo leonado, con una montera del mismo terciopelo; el aderezo de la yegua era de campo y de la jineta, asimismo de morado y verde; traía un alfanje morisco pendiente de un ancho tahalí de verde y oro, y los borceguíes eran de la labor del tahalí; las espuelas no eran doradas, sino dadas con un barniz verde, tan

62. M. BATAILlon, Erasmo y España, p. 792, n. 78.

63. M. Bataillon, Erasmo y España, p. 792.

64. M. Bataillon, Erasmo y España, p. 793.

65. M. Bataillon, Erasmo y España, p. 793.

66. A. SÁNCHEZ, "El Caballero del Verde Gabán", p. 181.

67. L. A. MURILLO, nota 5, p. 149, al capítulo XVI de la segunda parte.

68. L. A. MuRILLo, nota 7, p. 150, al capítulo XVI de la segunda parte. 
tersas y bruñidas, que, por hacer labor con todo el vestido, parecían mejor que si fuera de oro puro ${ }^{69}$.

Tres colores aparecen en la vestimenta del caballero: el verde omnipresente, de la montera a las espuelas, con toques de morado y leonado. El significado del verde es esperanza, amor el del morado; el leonado, como hemos visto al referirnos a Cardenio, cubre una gama que va de "gravedad y firmeza" en el Dechado de colores $^{70}$ a los problemas y angustias que proponía Kenyon al darlo como variante del amarillo ${ }^{71}$. No creo que el término se desprenda de ninguno de sus valores en Don Diego, creo, por el contrario, que morado y leonado aparecen como simples detalles que se marcan de forma discreta sobre el verde. La condición de enamorado y la de preocupado, en cierta medida moda de cortesanos unos años atrás, mostradas de forma discreta sobre un vestido verde de esperanza, podrían dar una idea completa del carácter de Don Diego y preparar el ideal de virtud y de aurea mediocritas que, por lo que sabemos de la pobre y ajetreada existencia de Cervantes, tenía tal vez mucho que ver con su ideal de vida.

Hilando con la mencionada hipótesis de Bataillon, el leonado pudiera significar el acicate del creyente por la vida eterna. Cierto que Don Diego afirma preferir la literatura profana a la devota ${ }^{72}$, pero ello pudiera manifestar, precisamente, la presencia de dicha preocupación, que lleva a evitar unos libros que podían llevarle a perder su equilibrio emocional.

Por otra parte, al relatar lo visto en la Cueva de Montesinos, describe Don Quijote, aquí en un pasaje directamente calcado de la literatura caballeresca, la vestimenta con que Montesinos sale a recibirlo a la puerta del "real y suntuoso palacio o alcázar"73 donde custodia el cuerpo muerto de Durandarte y a Belerma. La vestimenta del guardián del sepulcro y de los enamorados se ajusta de nuevo al código de los colores:

... abriéndose dos grandes puertas, vi que por ellas salía y hacia mí se venía un venerable anciano, vestido con un capuz de bayeta morada que por el suelo le arrastraba. Ceñíale los hombros y los pechos una beca de colegial, de raso verde; cubríale la cabeza una gorra milanesa negra, y la barba, canísima, le pasaba de la cintura ${ }^{74}$.

El color morado del amor es el que viste el guardián de la pareja de enamorados formada por Durandarte y Belerma, adornado con el verde de la esperanza (no olvidemos que los enamorados esperaban ser desencantados) en

69. Don Quijote, II, XVI, ed. cit., p. 661.

70. Dechado, villancico 3, ed. Macpherson, p. 39.

71. Vid. supra, p. 8.

72. "Tengo hasta seis docenas de libros, cuáles de romance, cuáles de latín [...]. Hojeo más los que son profanos que los devotos, como sean de honesto entretenimiento". Don Quijote, II, XVI, ed. cit., p. 664.

73. Don Quijote, II, XXIII, ed. cit., p. 724.

74. Don Quijote, II, XXIII, ed. cit., p. 724. 
torno al corazón y el negro de la fidelidad en la cabeza. La correspondencia de los colores con partes del cuerpo tan esenciales como el pecho o la cabeza (asiento del entendimiento y el sentimiento al menos desde Platón), deja lugar a pocas dudas sobre lo motivado de esta vestimenta.

Junto a todo ello, aparecen también referencias sueltas al color verde que subrayar determinadas prendas, tales como el parche que cubre el ojo de Maese Pedro ${ }^{75}$, o el traje con el que se muestra por primera vez la duquesa pues, aunque el verde era el color habitual de los trajes de caza (ejercicio en el que en ese momentos se entretienen los duques), centra sobre ella la atención cuando aparece:

... vio una gallarda señora sobre un palafrén o hacanea blanquísima, adornada de guarniciones verdes y con un sillón de plata. Venía la señora asimismo vestida de verde, tan bizarra y ricamente, que la misma bizarría venía transformada en ella ${ }^{76}$.

Del mismo modo son verdes las medias y la montera de Don Quijote y verde el traje que viste (y rasga) Sancho en la montería ${ }^{77}$.

Otro sentido parece tener el verde de las redes en las que caen Don Quijote y Sancho en su encuentro con la Arcadia fingida. ${ }^{78}$ El color del hilo con el que están tejidas las redes sirve para ocultarlas en la maleza y hacer caer en ellas a los pájaros, pero hace caer a caballero y escudero en un mundo ficticio del que van a salir mal parados y que va a iniciar, de forma muy sutil, el declive de Don Quijote hasta su derrota en la playa de Barcelona. No creo que sea casual que el verde que ha servido para destacar elementos hasta ahora sirva ahora para ocultar el primer choque de Don Quijote con la realidad tras el episodio en casa de los duques, donde ésta (representada por Doña Rodríguez, su hija, Tosilos y la cruel actitud del duque hacia ellos) ha quedado oculta a sus ojos.

Algo parecido sucede con el carmesí, color que simboliza la alegría y que aparece en detalles como las vestiduras de los criados de los duques que reciben a Don Quijote a las puertas del palacio:

Cuenta, pues, la historia que, antes que a la casa de placer o castillo llegasen, se adelantó el duque y dio orden a todos sus criados del modo que habían de tratar a don Quijote; el cual como llegó con la duquesa a las puertas del castillo, al instante salieron dél dos lacayos o palafreneros vestidos hasta en pies de unas ropas que llaman de levantar, de finísimo raso carmesí, y cogiendo a don Quijote en brazos, sin ser oído ni visto, le dijeron:

-Vaya la vuestra grandeza a apear a mi señora la duquesa ${ }^{79}$.

75. "Olvidábaseme decir como el tal Maese Pedro traía cubierto el ojo izquierdo y casi medio carrillo con un parche de tafetán verde" (Don Quijote, II, XXV, ed. cit., p. 744.

76. Don Quijote, II, XXX, ed. cit., p. 779.

77. Don Quijote, II, XXXIV, XLIV y XLVI, ed. cit., pp. 814, 882 y 895.

78. Don Quijote, II, LVIII, ed. cit., p. 990.

79. Don Quijote, II, XXXI, ed. cit., p. 784. 
Asimismo en el adorno de las galeras que Don Quijote visita, en su momento de mayor gloria pública, en Barcelona:

Arrojaron luego el esquife al agua, cubierto de ricos tapetes y de almohadas de terciopelo carmesí, y en poniendo que puso los pies en él don Quijote disparó la capitana el cañón de crujía y las otras galeras hicieron lo mesmo, y al subir don Quijote por la escala derecha toda la chusma le saludó como es usanza cuando una persona principal entra en la galera, diciendo “ $¡ \mathrm{Hu}, \mathrm{hu}, \mathrm{hu}$ !” tres veces ${ }^{80}$.

De este modo, Cervantes presenta al hilo del relato diferentes pinceladas de color que subrayan determinados aspectos de la realidad que rodea al caballero, de acuerdo con el sentido que estos colores tenían en el código de la época.

\section{CONCLUSIÓN}

Hasta aquí un primer repaso al uso del código de colores por parte de Cervantes. Hemos visto como dicho código, procedente de la ficción sentimental y caballeresca y refugiado en la poesía pastoril y el Romancero Nuevo, aparece tanto en la descripción de personajes secundarios del Quijote como en pinceladas que completan descripciones de personas o ambientes.

Sin duda alguna, este artículo (more cervantino) "propone algo y no concluye nada", pues el estudio del código de colores entre los siglos XIV y XVII está todavía por hacer. En ello me voy ocupando en el vagar que dejan otras cosas y de lo que va apareciendo, ceñido casi siempre al Quijote, he querido dejar constancia en estas páginas.

\section{BIBLIOGRAFÍA}

\section{TEXTOS CITADOS}

Cervantes, Miguel de, Don Quijote de La Mancha, edición del IV centenario, Madrid, Real Academia Española / Asociación de Academias de la Lengua Española, 2004.

-, Don Quijote de La Mancha, edición del Instituto Cervantes dirigida por Francisco Rico, Madrid, Galaxia Gutenberg / Círculo de Lectores / Centro para la Edición de los Clásicos Españoles, 2004.

-, Novelas ejemplares, edición de Florencio Sevilla Arroyo y Antonio Rey Hazas, Alcalá de Henares, Centro de Estudios Cervantinos, 1994.

Duque de Estrada, Diego, Comentarios del desengañado de sí mismo. Vida del mismo autor, edición de Henry Ettinghausen, Madrid, Castalia, 1982.

FERnÁNDEZ DE Heredia, Juan, El Secreto secretorum, edición de Juan Manuel Cacho Blecua, Zaragoza, Universidad de Zaragoza, 2003.

80. Don Quijote, II, LXIII, ed. cit., p. 1034. 
Plinio Segundo, Cayo, Historia natural de... traducida por el licenciado Gerónimo de Huerta, Madrid, Luis Sánchez, 1624.

Solís y Valenzuela, Pedro, El desierto prodigioso y prodigio del desierto, edición de Rubén Páez Patiño, Bogotá, Instituto Caro y Cuervo, 1977-1985.

Timoneda, Joan, Dechado de colores, Vid. MACPHERSON, I.

VALERA, Diego de, Espejo de verdadera nobleza, en Prosistas castellanos del siglo XV, I, edición de Mario Penna, Madrid, Atlas, 1959, pp. 89-116.

VIAJE de Turquía, edición de Fernando García Salinero, Madrid, Cátedra, 2000, 5. a ed.

Vicente de Burgos, Fray, Traducción de El Libro de Propietatibus Rerum de Bartolomé Anglicus, edición de M. ${ }^{a}$ Teresa Herrera y M. ${ }^{a}$ Nieves Sánchez, Salamanca, Universidad de Salamanca, 1999.

\section{ESTUDIOS}

Alonso, Dámaso, "Lope, Don Pedro de Cárdenas y los Cardenios", en Revista de Filología Española, XL (1956), pp. 70-90.

Alonso, Martín, Diccionario medieval español, Salamanca, Universidad Pontificia de Salamanca, 1983, 3 tomos.

Bataillon, Marcel, Erasmo y España, traducción de Antonio Alatorre, México, Fondo de Cultura Económica, 1995, 5. ${ }^{\text {a }}$ reimp. de la segunda edición, corregida y aumentada.

Corominas, J., y Pascual, J. A., Diccionario crítico etimológico castellano e hispánico; Madrid, Gredos, 6 vols.

Covarrubias, Sebastián de, Tesoro de la lengua castellana o española, edición de Felipe C. R. Maldonado revisada por Manuel Camarero, Madrid, Castalia, Nueva Biblioteca de Erudición y Crítica, 1995.

-, Suplemento al 'Tesoro', edición de Georgina Dopico y Jacques Lezra, Madrid, Polifemo, 2001.

Duncan, R. M.; “Adjetivos de color en el español medieval”, en Anuario de Estudios Medievales 5 (1968), pp. 463-72.

-, "Color Words in Medieval Spanish", en Studies in Honor of Lloyd A. Kasten, Madison, Hispanic Seminar of Medieval Studies, 1973, pp. 53-71.

GoldBerg, Harriet, "A Reappraisal of Color Symbolism in the Courtly Prose Fiction of Late-Medieval Castile", en Bulletin of Hispanic Studies, 69 (1992), pp. 221-237.

KenYon, Herbert, "Color Symbolism in Early Spanish Ballads" en Romanic Rewiew, 6 (1915), pp. 327-340.

MaCPHERSON, Ian, "Juan Timoneda's, Dechado de colores", en "Never-ending Adventure": Studies in Medieval and Early Modern Spanish Literature in Honor of Peter N. Dunn, editado por Eward H. Friedman y Harlan Sturm, Newark, Delaware, Juan de la Cuesta, 2004, pp. 37-62.

MuRILLO, Luis Andrés, edición, introducción y notas a Don Quijote de La Mancha, Madrid, Castalia, 1987, 2 tomos.

Real ACADEMIa EsPañola, Diccionario de autoridades, edición facsímil, Madrid, Gredos, 1990, 3 vols.

ReYre, D., Dictionnaire des noms des personnages du Don Quijote et de Cervántes, París, Editions Hispaniques, 1980.

SÁnCHEZ, Alberto, "El Caballero del Verde Gabán” en Anales Cervantinos, IX, 1961-62, pp. 169-201.

SATAKE, Kenichi, "En torno a Cardenio en el Quijote: locura, suerte y honor", en Anales cervantinos, XXIV, 1986, pp. 93-102. 


\title{
Resumen
}

Los nombres de color tuvieron un significado simbólico entre los siglos XIV y XVII que restringía en cierto modo su uso. En este artículo, el autor ejemplifica este uso en varios episodios de Don Quijote y las Novelas ejemplares.

Palabras clave: Nombres de color, Cervantes, Don Quijote de la Mancha. Novelas ejemplares.

\begin{abstract}
Colour terms had during XIV and XVII centuries a simbolic meaning which restrict their use in a certain way. In this article, the author exemplizes this use with some passages of Don Quijote and Novelas ejemplares.
\end{abstract}

Key words: Color terms, Cervantes, Don Quijote de la Mancha. Novelas ejemplares. 